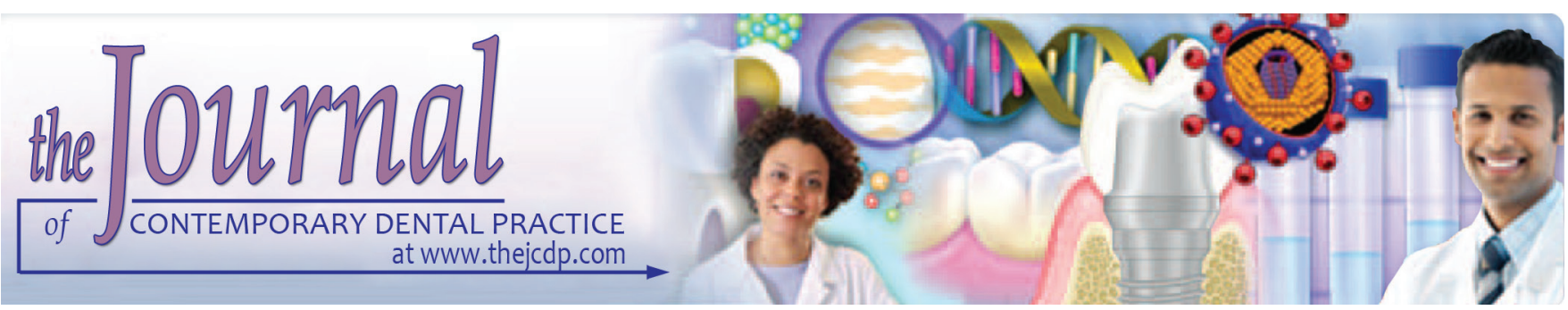

\title{
Trauma due to Self-aggression in Patient with Waardenburg Syndrome associated with Congenital Anomalies
}

\author{
${ }^{1}$ Sara Nader Marta, ${ }^{2}$ Roberto Yoshio Kawakami, ${ }^{3}$ Claudia Almeida Prado Piccino Sgavioli \\ ${ }^{4}$ Ana Eliza Correa, ${ }^{5}$ Guaniara D’Árk de Oliveira El Kadre, ${ }^{6}$ Ricardo Sandri Carvalho
}

\begin{abstract}
Waardenburg syndrome (WS) is an inherited autosomal dominant genetic disorder presenting variable penetrance and expressivity, with an estimated prevalence of 1:42,000. Clinical characteristics of WS include lateral displacement of the internal eye canthus, hyperplasia of the medial portion of the eyebrows, prominent and broad nasal base, congenital deafness, pigmentation of the iris and skin, and white forelock. A 24-year-old male patient, previously diagnosed with WS, was referred to the Special Needs Dental Clinic of Sacred Heart University, Bauru, Brazil. Parents reported that the patient was experiencing self-mutilation, particularly in the oral region. He presented multiple congenital anomalies, including anophthalmia, mental retardation, low-set ears, and leg deformities. Clinical oral examination revealed hypodontia, abnormalities in dental morphology, extensive dental caries, periodontal disease, and fistulae. Extensive scars on the tongue, lips, and hands caused by self-mutilation were also observed. In accordance with his family and neurologist, full-mouth extraction under general anesthesia was performed, especially considering his severe self-aggressive behavior and the necessity to be fed with soft-food diet due to his inability to chew. After the surgical procedure, a significant reduction in the patient's irritability and gain of weight were reported in the followups of 30,60 , and 180 days.
\end{abstract}

Keywords: Autosomal dominant, Genetic disorder, Waardenburg syndrome.

How to cite this article: Marta SN, Kawakami RY, Sgavioli CAPP, Correa AE, D'Árk de Oliveira El Kadre G, Carvalho RS. Trauma due to Self-aggression in Patient with Waardenburg Syndrome associated with Congenital Anomalies. J Contemp Dent Pract 2016;17(8):702-705.

Source of support: Nil

Conflict of interest: None

1,2,4-6 Department of Dentistry, Universidade do Sagrado Coração, São Paulo, Brazil

${ }^{3}$ Department of Health, Secretaria Municipal da Saúde, Bauru São Paulo, Brazil

Corresponding Author: Sara Nader Marta, PhD, Department of Dentistry, Universidade do Sagrado Coração, São Paulo Brazil, Phone: +1421077000, e-mail: sara@nadermarta.com.br

\section{INTRODUCTION}

Klein-Waardenburg syndrome (WS) is a rare autosomal dominant disorder with variable penetrance, and there are several known clinical phenotypes of WS. Waardenburg syndrome was first described in 1951 by Petrus Johannes Waardenburg ${ }^{1}$ and has an estimated prevalence of one in every 42,000 births. The genders are equally affected. Six genes are involved in this syndrome: PAX3 (encoding the paired box 3 transcription factor), MITF (microphthalmiaassociated transcription factor), EDN3 (endothelin 3), EDNRB (endothelin receptor type B), SOX10 (encoding the Sry BOX10 transcription factor), and SNAI2 (snail homolog 2). These six genes are affected with variable frequency in WS. ${ }^{2}$ Greater than $90 \%$ of individuals who meet the diagnostic criteria for WS have identifiable mutations in the PAX3 gene, and the identification of this gene has been used for genetic counseling. ${ }^{3}$

The most frequent clinical signs of WS include sensorineural hearing loss (congenital deafness and deafness secondary to cochlear malformations), lateral displacement of internal eye canthi (telecanthus), hyperplasia of the medial portion of the eyebrows (synophrys), a prominent and broad nasal base, alterations in iris and skin pigmentation, and white forelock or premature graying. Gut and bone malformations, neural tube defects, cleft lip and palate, limb abnormalities, and Hirschsprung disease may also be associated with WS. Other severe malformations, such as cyclopia and synophthalmia, are rarely described and are usually not compatible with life. ${ }^{4,5}$

Waardenburg syndrome appears to be associated with the defective migration of neural crest cells during the third month of pregnancy. These neural crest cells eventually give rise to melanocytes, sympathetic ganglia, sensory components of the cranial and spinal nerves, and membranous bones of the face and the palate, dentin, and visceral ganglia. Defects in the formation of these 
structures can account for all of the clinical signs of WS described in the literature. ${ }^{6,7}$

This case report describes the treatment of an individual diagnosed with WS who presented characteristic clinical signs, severe associated malformations, and marked self-aggression.

\section{CASE REPORT}

A 24-year-old male Caucasian patient was referred to the Special Needs Dental Clinic at Sacred Heart University, Bauru, Brazil, accompanied with his parents whose major complaint was the traumatic lesions their son was suffering from due to self-mutilation, especially in the tongue and lower lip. They suspected that this behavior was a reaction to toothache and also when he was extremely annoyed or upset. Previous reports from geneticists and neurologists confirmed the diagnosis of WS type III, which is associated with multiple congenital anomalies. Clinical examination revealed that the patient presented with hearing loss, hypochromic skin spots, severe intellectual disability, lower limb deformities, and anophthalmia (Figs 1A to G). In addition, the patient exhibited low-set ears, bilateral tragus hypoplasia, indentations on the left earlobe and nasal bridge margin, retrognathia, macrostomia, bilateral clinodactyly, absence of the left second toe, total syndactyly of the left third and fourth toes, and absent distal phalanx on the right second toe. Because of the patient's condition, he was completely dependent upon caretakers for his basic needs (hygiene, feeding, and movement).

Carbamazepine (600 mg/day), risperidone ( $4 \mathrm{mg} /$ day), and promethazine ( $25 \mathrm{mg}$ / day) were administered daily to the patient. Clinical oral examination revealed a fissure of the right lip commissure. Furthermore, hypodontia of the second premolars, third molars, maxillary and mandibular lateral incisors, and mandibular central incisors was observed. The maxillary central incisors were peg shaped, and there was a wide diastema between the incisors, which presented sharp edges. Shape and position of these teeth favored self-mutilation of the tongue, lower lip, and hands. Scars caused by traumatic bite lesions were observed (Figs 2A to D).

The posterior teeth were extensively damaged and showed mobility as a result of periodontal disease and fistulae in the upper molar area, clinically characterizing an infectious process. The lack of oral hygiene had led

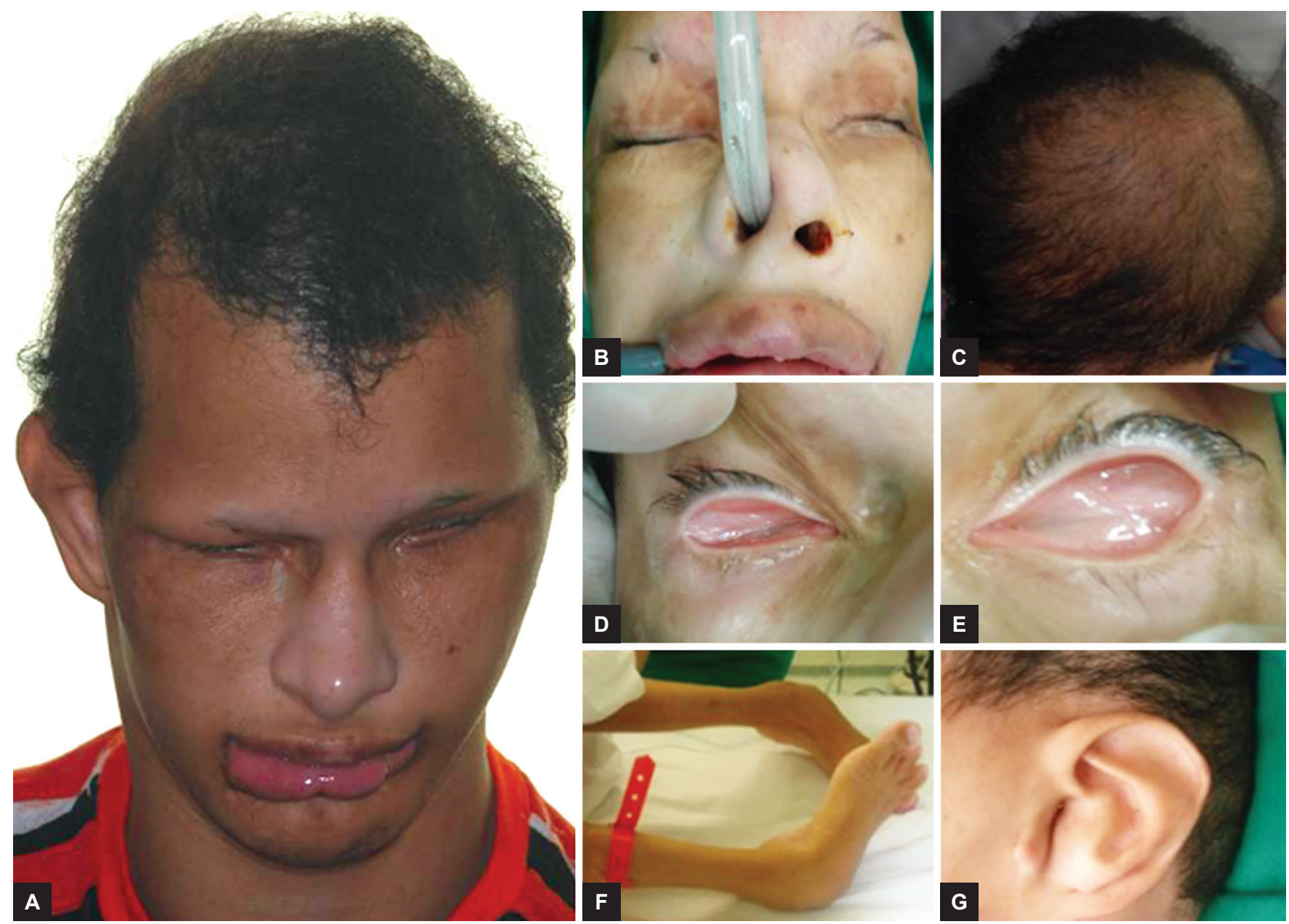

Figs 1A to G: (A) Frontal view of the patient. Note the hypochromic spots around the nose, forehead, and mouth; (B) preparation of the patient for surgery. The surgery was focused on treating the hypochromic spots and poliosis of the eyebrows; (C) early alopecia; (D) and (E) right and left anophthalmia respectively; $(F)$ deformities of the legs and feet; and (G) low-set and malformed ears 

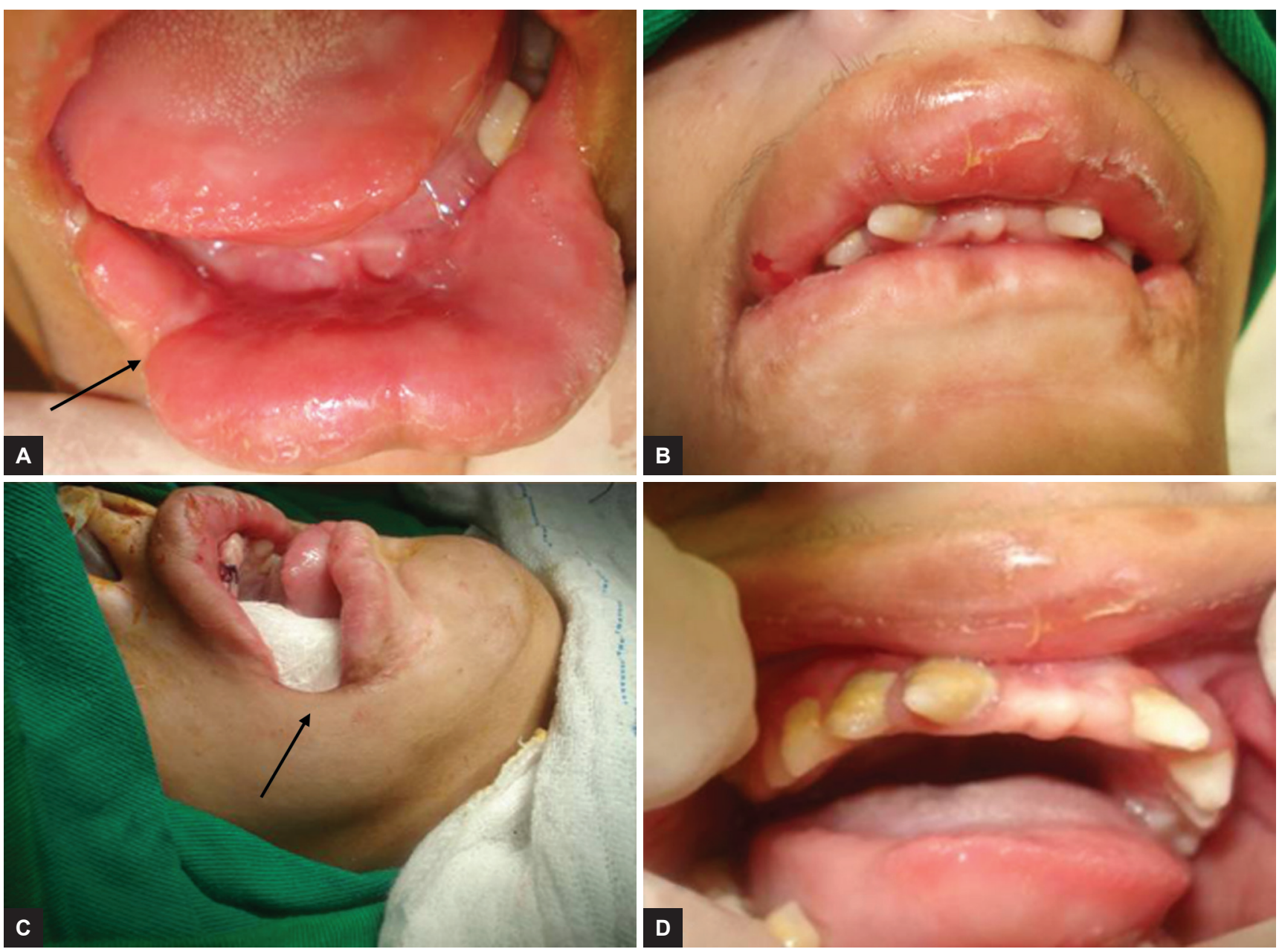

Figs 2A to D: (A) Lower lip mutilation by self-aggression (bites); (B) extraoral aspect: presence of scars and hypochromic spots on the skin; (C) fissure of the lip commissure; and (D) hypodontia and acute peg-shaped teeth, which were used in self-aggressive behaviors

to dental plaque and calculus accumulation and a fetid smell. The patient received soft and/or liquid diet due to his inability to chew. Instead of chewing, he would hit his chin region against his clavicle, which resulted in skin lesions. Scars resulting from this behavior were also observed during the clinical examination.

\section{TREATMENT}

After analyzing and discussing the case with the family and the patient's neurologist, a full-mouth extraction was chosen for treatment. The factors that led to this decision included the severe self-aggression and the inability to use his teeth for chewing. Surgical treatment was performed under general anesthesia in a hospital. Previous radiographic examination had not been performed because of the patient's severe intellectual disability. Following the anesthetic procedures, an incision was made through the extent of the lesion in the buccal and palatal/lingual alveolar ridges of the dental arches. Subsequently, dissection, extraction, alveolar ridge regularization, and suture were performed. All of the patient's 18 teeth were extracted. We have verified that not only the crowns of the central incisors were deformed, but also their roots had dilacerations. The roots of several other teeth were deformed as well (Figs 3A and B).

The follow-up appointments at 30,60, and 180 days revealed an improvement in the patient's oral and general clinical status. A significant reduction in the patient's irritability was reported. This improvement may have been a consequence of removing the infection sites, decreasing the pain in the oral cavity, and eliminating the possibility of biting and self-aggression. These changes have contributed to a better quality of life for the patient and his caretakers.

\section{DISCUSSION}

Oral deformities in WS may be associated with the defective migration of neural crest cells during the third month of pregnancy. Abnormalities in this process can explain all of the clinical signs of WS that have been described in the literature, ${ }^{6,8,9}$ as well as those that were observed in this case. The abnormalities of the shape, number, and positions of the teeth are emphasized.

Individuals with WS may not always present with the full spectrum of clinical symptomatology associated 

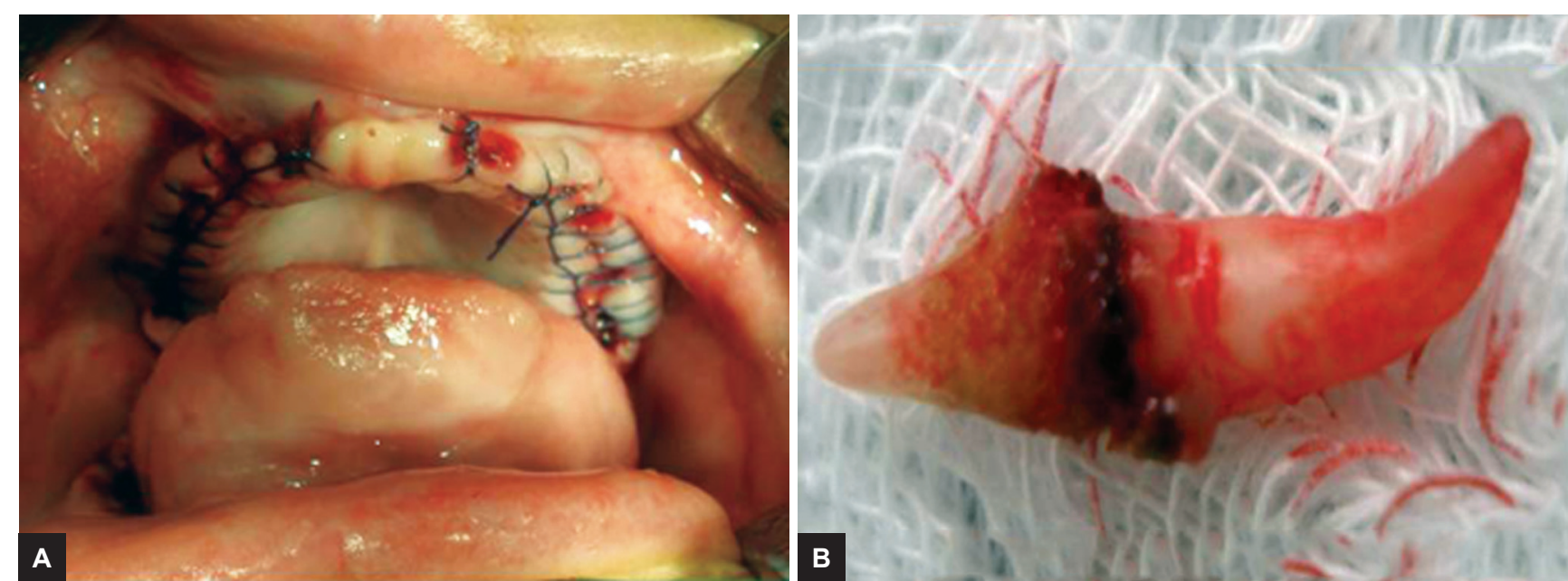

Figs 3A and B: (A) Immediate postoperative image; and (B) peg-shaped teeth with root dilaceration

with WS. However, the severity of the present case was exacerbated by the presence of multiple congenital anomalies. These anomalies included severe mental retardation and anophthalmia. The patient also suffered marked trauma as a result of self-aggression. Self-injurious behavior, which was present in this case, has not been commonly associated with WS in previous reports. Instead, self-aggression is a component of Lesch-Nyhan syndrome, which is an X-linked disease caused by deficient activity of the purine salvage enzyme hypoxanthineguanine phosphoribosyltransferase. This defect leads to hyperuricemia and other clinical consequences of the syndrome. Lesch-Nyhan syndrome was the first example of a stereotyped pattern of abnormal behavior with an identified fundamental molecular etiology, and the syndrome has been shown to be associated with the absent activity of a particular enzyme. ${ }^{10}$

Dental treatment, i.e., a full-mouth extraction, was performed. Other alternatives of more conservative treatments were previously considered, such as recontouring of the incisors, periodontal and endodontic approach, and restoring treatment. However, these possibilities were discarded because they would not impede continuous selfmutilation, and the problem would remain. The proposed treatment significantly stopped bite trauma. Furthermore, the parents reported calmer behavior upon postoperative follow-up. This improvement may also have been a result of pain and oral infected site extinguishment. The currently published and reviewed studies have not already reported the associated comorbidities present in this case. As a result, establishing parameters for comparison was difficult, particularly with respect to treatment selection. This case highlights the importance of an interdisciplinary professional team that is focused on the well-being and quality of life of these special patients.

\section{REFERENCES}

1. Waardenburg PJ. A new syndrome combining developmental anomalies of the eyelids, eyebrows and nose root with pigmentary defects of the iris and head hair and with congenital deafness. Am J Hum Genet 1951 Sep;3(3):195-253.

2. Pingault V, Ente D, Moal FD, Goossens M, Marlin S, Bondurand N. Review and update of mutations causing Waardenburg syndrome. Hum Mutat 2010 Apr;31(4):391-406.

3. Kozawa M, Kondo H, Tahira T, Hayashi K, Uchio E. Novel mutation in PAX3 gene in Waardenburg syndrome accompanied by unilateral macular degeneration. Eye (Lond) 2009 Jul;23(7):1619-1621.

4. Dantas AM, Costa JG, Patras AL, Couto AS Jr. Cyclopia and synophthalmia: congenital facial anomalies with neurological defects. Orbit 1997 Jan;16(1):45-52.

5. Silva PCV, Rangel P, Couto A Jr. Síndrome de Waardenburg tipo I: relato de caso [Waardenburg Syndrome type I: case report]. Arq Bras Oftalmol 2011 May-Jun;74(3):209-210.

6. Martins CHF, Yoshimoto FR, Freitas PZ. Síndrome de Waardenburg: achados audiológicos em dois irmãos [Waardenburg Syndrome: audiological findings in two siblings]. Rev Bras Otorrinolaringol 2003 Feb;69(1):117-119.

7. Wang J, Li S, Xiao X, Wang P, Guo X, Zhang Q. PAX3 mutations and clinical characteristics in Chinese patients with Waardenburg syndrome type 1. Mol Vis 2010 Jun;16:1146-1153.

8. Omar ED, Oliveira ZNP, Rivitti-Machado MCM. Você conhece esta síndrome? Síndrome de Waardenburg (SW) tipo 2B [Do you know this syndrome? Waardenburg Syndrome (WS) type 2B]. An Bras Dermatol 2007;82(2):187-189.

9. Ghosh SK, Bandyopadhyay D, Ghosh A, Biswas SK, Mandal RK. Waardenburg syndrome: a report of three cases. Indian J Dermatol Venereol Leprol 2010 Sep-Oct;76(5):550-552.

10. Schretlen DJ, Ward J, Meyer SM, Yun J, Puig JG, Nyhan WL, Jinnah HA, Harris JC. Behavioral aspects of Lesch-Nyhan disease and its variants. Dev Med Child Neurol 2005 Oct;47(10):673-677. 